\title{
Simulation of Three-dimensional Vibrated Fluidized Bed Dryer Using Distinct Element Method
}

\author{
S. Wongsiriwan ${ }^{1}$, Thongchai Rohitatisha Srinophakun ${ }^{2 *}$, and Pakon Laopreecha ${ }^{3}$ \\ ${ }^{1}$ Chemical Engineering Practice School, King Mongkut's University of Technology Thonburi, Bangkok 10500, Thailand \\ ${ }^{2}$ Department of Chemical Engineering, Kasetsart University \\ Bangkok 10900, Thailand \\ ${ }^{3}$ Department of Chemical Engineering, Kasetsart University \\ Bangkok 10900, Thailand \\ Corresponding author's email: fengtcs [AT] hotmail.com
}

\begin{abstract}
The particle motion, temperature behavior, and drying rate of particle inside a vibrated fluidized bed dryer were numerically investigated in this work. In the simulation, the Distinct Element Method (DEM) based on the Newton's second law of motion was used to solve the particle motion. The physical aspects of fluid motion and heat transfer were obtained by applying Computational Fluid Dynamics (CFD) technique. For the drying of particle, only the constant rate period was considered in order to save the computational time. Programming was developed in Standard-C language and using MATLAB to visualize the results. In the simulation, 2,000 particles with stiffness 800 $N \mathrm{~m}-1$ were simulated in a rectangular bed. The developed model was validated with an experimental result of Gupta et al. [1]. The program was then used to study the effect of superficial gas velocity (U0), frequency of vibration (f) and amplitude of vibration (a) in fluidized bed dryer. At low velocities and no vibration of bed, particles in the bed were not fluidized but smoothly circulated. Thus, the heat transfer occurred only near the orifice. When superficial gas velocity increased, the fluidization of the particles was observed. The fluidization and drying rate improved with increased in superficial velocity for both vibrated fluidized bed and stationary bed. With introducing of vibration, the fluidization behavior of the particle was improved. The particles in the bed were well mixed and also increased the drying rate. From the simulation results, increasing of frequency and amplitude could not significantly improve rate of drying.
\end{abstract}

Keywords - Vibrated Fluidized Bed / Distinct Element Method (DEM) / Computational Fluid Dynamic (CFD)

\section{INTRODUCTION}

Fluidization is an effective technique in solid processes such as chemical reaction and drying. The solid phase is fluidized to achieve effective heat and mass transfer between gas and solids. Some particles are difficult to fluidize due to wide particle size distribution, particle-to-particle adhesive forces (stickiness), a vibrated fluidized bed has been introduced. Nevertheless, it is impossible to observe the phenomena directly which occur inside the bed. Therefore, a numerical model was developed to describe the fluidization behavior. The gas-solid flow in a fluidized bed and vibrated fluidized bed can be modeled by a combined approach of distinct element method and computational fluid dynamics (DEM-CFD). The motion of individual particles is obtained by solving Newton's second law of motion and gas flow by the Navier-Stokes equation. The advantage of using this combined approach is that the information of the particle and fluid motion can be precisely obtained in more detail than that from the experiment. However, a disadvantage is that it takes long computational time. The Distinct Element Method (DEM) established by Cundall and Strack is a numerical model capable of describing the mechanical behavior of assemblies of discs and spheres. This method is based on the use of an explicit numerical scheme in which the interaction of the particles is monitored contact by contact and the motion of the particles modeled particle by particle. The time step used in the calculation should be small to maintain a reliable result, but the smaller time step, the longer computational time. Therefore, an appropriate time step should be chosen to avoid step disturbances that can propagate [2].

Computational Fluid Dynamics (CFD) is the analysis of system involving fluid flow, heat transfer, and associated phenomena by mean of computer-based simulation [3]. The equations usually are partial differential equations which cannot be solved analytically. Therefore, a discretization method is applied to approximate the differential equations by a 
system of algebraic equation. The aim of this work is to generate a DEM-CFD model that can describe the phenomena of vibrated fluidized bed dryer. The motion of particle and fluid are modeled in three-dimensional with simultaneous heat and mass transfer..

\section{THEORY}

\subsection{Vibrated Fluidized Bed System}

The fluidization is less effective when applied for the particles that have wide range of particle size distribution, low strength or sticky. Therefore, a vibrated fluidized bed which refers to a fluidized bed wherein the complete assembly is vibrated at a relatively high frequency and with small amplitude has been introduced.

\subsection{Distinct Element Method}

Individual particle motion is traced by using DEM. From the Newton's second law, the total force acting on the particle must be known in order to calculate the motion of that particle. The equations for total force acting on an individual particle for translational and rotational can be respectively written as

$$
\begin{gathered}
\mathrm{m} \frac{\mathrm{dv}}{\mathrm{dt}}=\mathrm{f}_{\mathrm{c}}+\mathrm{f}_{\mathrm{d}}+\mathrm{f}_{\mathrm{f}}+\mathrm{mg} \\
\mathrm{I} \frac{\mathrm{d} \omega}{\mathrm{dt}}=\mathrm{T}
\end{gathered}
$$

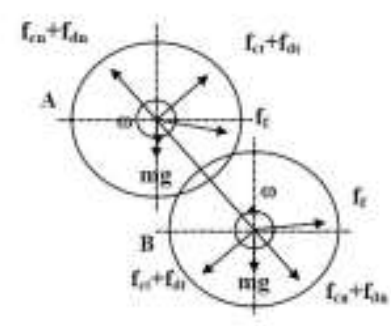

Figure 1: Schematic diagram of particle-particle collision

The DEM was used in this work to calculate the contact forces. The calculation of particle-particle contact is expressed in the following while the collision between spheres and walls are modeled in a similar manner. The schematic diagram of particle-particle collision is shown in Figure 1. To find the contact force between sphere A and B, the calculation starts with the calculation of unit normal vector, $n$, from the center of sphere A to that of sphere B

$$
\mathrm{n}_{\mathrm{i}}=\left(\mathrm{u}_{\mathrm{B}, \mathrm{i}}-\mathrm{u}_{\mathrm{A}, \mathrm{i}}\right) / \mathrm{d}
$$

Where $\mathrm{d}$, the distance between the centers, is given by

$$
\mathrm{d}=\left(\sum_{\mathrm{i}}\left(\mathrm{u}_{\mathrm{B}, \mathrm{i}}-\mathrm{u}_{\mathrm{A}, \mathrm{i}}\right)\left(\mathrm{u}_{\mathrm{B}, \mathrm{i}}-\mathrm{u}_{\mathrm{A}, \mathrm{i}}\right)\right)^{1 / 2}
$$

The velocity of $\mathrm{B}$ with respect to $\mathrm{A}$, represented as $v_{\mathrm{i}}$ is, 


$$
\mathrm{v}_{\mathrm{i}}=\mathrm{v}_{\mathrm{B}, \mathrm{i}}-\mathrm{v}_{\mathrm{A}, \mathrm{i}}
$$

The vectors that represent the normal, vn,i, and tangential, $v_{\mathrm{t}, \mathrm{i}}$, components of $v_{\mathrm{i}}$ are

$$
\begin{aligned}
& v_{n, i}=v_{j} n_{j} n_{i} \\
& v_{t, i}=v_{i}-v_{n, i}
\end{aligned}
$$

Vector $\omega_{\mathrm{i}}$ represented the angular velocity of the center of $\mathrm{B}$ with respect to that of $\mathrm{A}$ is normal to both $v_{\mathrm{n}, \mathrm{i}}$ and $v_{t, i}$. It is the angular velocity of the contact normal from the center of $A$ to that of $B$. The magnitude of $\omega_{\mathrm{i}}$ is equal to $v_{t}=\left(v_{t} v_{t}\right)^{1 / 2}$ divided by the distance $d$. Thus $\omega_{i}$ may be represented as follows

$$
\omega_{\mathrm{r}, \mathrm{i}}=\varepsilon_{\mathrm{ijk}} \mathrm{n}_{\mathrm{j}} v_{\mathrm{t}, \mathrm{k}} / \mathrm{d}
$$

Where, eijk is the alternating tensor of third rank.

The shear velocity, $v_{\mathrm{s}, \mathrm{i}}$, across the contact is a vector that composed of the tangential velocity, $v_{\mathrm{t}, \mathrm{i}}$, and a component due to the rotation of the two spheres. The shear velocity is

$$
v_{\mathrm{s}, \mathrm{i}}=v_{\mathrm{t}, \mathrm{i}}+\varepsilon_{\mathrm{ijk}} \mathrm{n}_{\mathrm{j}}\left(\omega_{\mathrm{A}, \mathrm{k}} \mathrm{r}_{\mathrm{A}}+\omega_{\mathrm{B}, \mathrm{k}} \mathrm{r}_{\mathrm{B}}\right)
$$

The normal force $f_{c n}, i$ is in the direction of the normal vector, and has a magnitude $f_{c n}$

$$
\mathrm{f}_{\mathrm{cn}, \mathrm{i}}=\mathrm{f}_{\mathrm{cn}} \mathrm{n}_{\mathrm{i}}
$$

The magnitude of the normal force is updated at every time step. With $\mathrm{k}$ representing the normal stiffness, the $\mathrm{n}$ normal force at the contact is updated as

$$
\mathrm{f}_{\mathrm{cn}}=\mathrm{f}_{\mathrm{cn}}^{\prime}-\mathrm{v}_{\mathrm{n}} \mathrm{k}_{\mathrm{n}} \Delta \mathrm{t}
$$

Where $\mathrm{f}_{\mathrm{cn}}^{\prime}$ is the normal force at the end of the previous time step, and $v_{\mathrm{n}}=\left(v_{\mathrm{n}, \mathrm{i}} \mathrm{v}_{\mathrm{n}, \mathrm{i}}\right)^{1 / 2}$. Both magnitude and direction of shear force, $\mathrm{f}_{\mathrm{cs}, \mathrm{i}}$, must be updated at each time step. A change in the direction of the shear force is caused due to a change in the orientation of the contact normal and by the incremental shear displacement $v_{\mathrm{s}, \mathrm{i}} \Delta \mathrm{t}$ across the contact. If $\mathrm{f}_{\mathrm{cs}, \mathrm{i}}^{\prime}$ represents the shear force at the end of the previous time step, the shear force $\mathrm{f}_{\mathrm{cs}, \mathrm{i}}$ at the end of the current time step, with $\mathrm{k}_{\mathrm{s}}$ representing the shear stiffness at the contact is given by

$$
\mathrm{f}_{\mathrm{cs}, \mathrm{i}}=\mathrm{f}_{\mathrm{cs}, \mathrm{j}}^{\prime}-\mathrm{k}_{\mathrm{s}} \mathrm{v}_{\mathrm{s}, \mathrm{i}} \Delta \mathrm{t}
$$

First, the magnitude of the shear force is calculated to see if its value is greater than the maximum that is permitted. The maximum permissible shear force, $\mathrm{f}_{\mathrm{s}, \max }=\mu \cdot \mathrm{f}_{\mathrm{cn}}$, where $\mu$ is the coefficient of friction at the contact. If this is the case, it is assumed that slip occurs and the magnitude of the shear force is scaled down to $\mu \mathrm{f}_{\mathrm{cn}}$. The calculation cycle is continued with this new value of the shear force. Otherwise, the calculated value is taken.

Since the system tends to be stationary due to the inelastic collisions between particles if no external energy is added, the viscous contact damping force is introduced to consume the system energy during particle collisions. The viscous contact damping forces are given by

$$
\mathrm{f}_{\mathrm{dn}, \mathrm{i}}=-\eta_{\mathrm{n}} v_{\mathrm{n}} \mathrm{n}_{\mathrm{i}}
$$




$$
\mathrm{f}_{\mathrm{ds}, \mathrm{i}}=-\eta_{\mathrm{s}} \mathrm{v}_{\mathrm{s}, \mathrm{i}}
$$

In the above expression, $\mathrm{f}_{\mathrm{dn}, \mathrm{i}}$ and $\mathrm{f}_{\mathrm{ds}, \mathrm{i}}$ stand for the components of the normal and the shear contact damping forces where $\eta_{\mathrm{n}}$ and $\eta_{\mathrm{s}}$ stand for normal and shear contact damping coefficients.

In modeling inter-particle force, three parameters, namely the spring constant, the coefficient of friction, and viscous contact damping coefficient, must be available. Among these parameters, only the friction coefficient, $\gamma$, is measurable and can be described an empirical value. Therefore, the stiffness or spring constant, $\mathrm{k}$, must be determined first. The stiffness can be calculated using the Hertzian contact theory when physical properties such as the Young's modulus and Poisson ratio are known. For the case of two spheres of the same radius $\mathrm{R}, \mathrm{k}$ is expressed by;

$$
k=\frac{\sqrt{2 R} E_{p}}{3\left(1-\sigma_{p}^{2}\right)}
$$

and $\mathrm{k}$ for contact between a sphere and wall is given by

$$
\mathrm{k}=\frac{4 \sqrt{\mathrm{R}}}{3} / \frac{1-\sigma_{\mathrm{p}}^{2}}{\mathrm{E}_{\mathrm{p}}} \cdot \frac{1-\sigma_{\mathrm{w}}^{2}}{\mathrm{E}_{\mathrm{w}}}
$$

Fluid drag force is another force between particle and fluid. It depends on the relative velocity of fluid and particle, and the presence of other surrounding particles. This force represents the interaction between the fluid and the particles, and is given by

$$
\mathrm{f}_{\mathrm{f}, \mathrm{i}}=\frac{\beta}{\rho_{\mathrm{g}}}\left(\overline{\mathrm{v}}_{\mathrm{p}, \mathrm{i}}-\mathrm{u}_{\mathrm{i}}\right)
$$

Where $\bar{v}_{p, i}$ is the averaged of the particle velocities. The coefficient $\beta$ is given by Ergun's [4] equation for the dense region and the equation derived by $\mathrm{Wen}$ and $\mathrm{Yu}[5]$ for the dilute region;

\subsection{Drying of Solids}

Drying is the process of thermally removing volatile liquid from a solid product. The moisture contained in a wet solid exerts a vapor pressure to an extent depending upon the moisture, the nature of solid and the temperature. A wet solid exposed to a continuous supply of gas continuous to lose moisture until the vapor pressure of the moisture in the solid is equal to the partial pressure of the vapor in the gas. Further exposure to this air for in definitely long periods will not bring about any additional loss of moisture.

The drying behavior of solids can be characterized by measuring the moisture content loss as a function of time. It can be divided into heating-up period, constant rate period and falling rate period. And the method used to calculate the temperature of fluid is similar to the method used for fluid motion. The energy equation for fluid is given by;

$$
\frac{\partial\left(c_{p f} \rho_{f} \varepsilon T_{f}\right)}{\partial t}+\nabla \cdot\left(c_{p f} \rho_{f} \varepsilon u T_{f}\right)=\frac{6(1-\varepsilon)<h\left(T_{p}-T_{f}\right)>}{d_{p}}
$$

Where $h=$ heat transfer coefficient estimated by Ranz-Marshall correlation

$S p=$ external surface area of a particle

$$
\mathrm{Nu}=2.0+0.6 \operatorname{Pr}^{1 / 3} \operatorname{Re}_{\mathrm{p}}^{1 / 2}
$$




\section{PROGRAMMING}

\subsection{Assumption}

1. Particles are concerned as Geldart group D particle (no effect of agglomerate).

2. Particles are Nonhygroscopic capillary-porous media in spherical shape.

3. The calculation is based on a three- dimensional model.

4. The particle-to-particle adhesion forces and buoyancy force are neglected

5. Particles have a soft sphere interaction expressed by a Hookean linear spring, a dash pot and a friction slider with Coulomb's friction law.

6. Gas is inviscid except for gas-particle vicinity

7. The temperature of particle is uniform.

8. Physical properties of the gas and heat capacity of the particle are constant.

9. Ranz-Marshall correlation (1952) is applied to calculate the particle-to-gas heat transfer coefficient.

10. Particle-to-particle heat transfer is neglected because of short contact time.

11. Heat loss through the bed wall is neglected.

12. The radiation heat transfer is unimportant.

13. Air velocity is high enough so that the effect of vaporized water to the gas phase can be negligible.

14. The drying process concerned in this work is only in constant rate period. The important simulation parameters are shown in Table 1.

Table 1: Parameters for the simulation

\begin{tabular}{|c|c|c|}
\hline Particle & & Gas Phase \\
\hline $\begin{array}{l}\text { Diameter } 0.0025 \mathrm{~m} \\
\text { Density of bulk particle } 887 \mathrm{~kg} \mathrm{~m}^{-3} \\
\text { Stiffness } 800 \mathrm{~N} \mathrm{~m}^{-1} \\
\text { Coefficient of friction } 0.3 \\
\text { Viscous contact damping } 0.018 \\
\text { Heat capacity } 962 \mathrm{~J}(\mathrm{~kg} \mathrm{~K})^{-1} \\
\text { Density of water content } 1000 \mathrm{~kg} \mathrm{~m}^{-3}\end{array}$ & & $\begin{array}{ll}\text { Density } & 1.205 \mathrm{~kg} \mathrm{~m}^{-3} \\
\text { Viscosity } & 1.81 \times 10^{-5} \mathrm{~N} \mathrm{~m}^{-2} \mathrm{~s}^{-1} \\
\text { Heat capacity } & 1019.7\left(\mathrm{~kg} \mathrm{~K}^{-1}\right. \\
\text { Heat conductivity } & 0.03356 \mathrm{~W}(\mathrm{~m} \mathrm{~K})^{-1} \\
\text { Dry-bulb temperature } & 320 \mathrm{~K} \\
\text { Wet-bulb temperature } & 303.15 \mathrm{~K}\end{array}$ \\
\hline $\begin{array}{l}\text { Chamber cross-section } 50 \text { x } 50 \mathrm{~mm} \text { Cell width } \\
\text { Cell height } \quad 20 \mathrm{~mm} \\
\text { Cell depth } \quad 10 \mathrm{~mm}\end{array}$ & $10 \mathrm{~mm}$ & $\begin{array}{lc}\text { Number of particle } & 2000 \\
\text { Number of orifice } & 5 \\
\text { Orifice length } & 10 \mathrm{~mm} \\
\text { Orifice width } & 10 \mathrm{~mm}\end{array}$ \\
\hline
\end{tabular}

The calculation flow diagram used in programming is shown in Figure 2. 


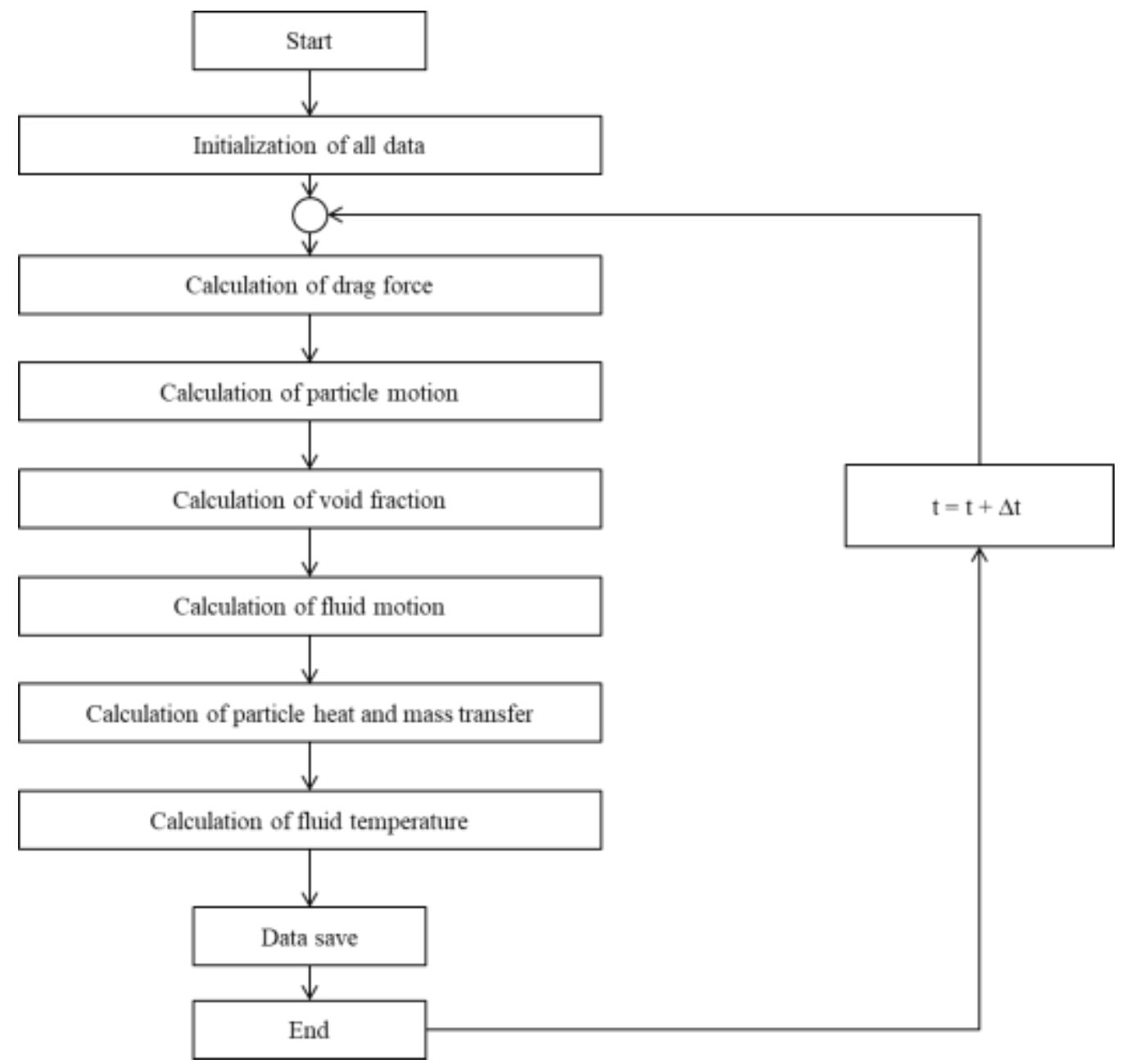

(a) Overall flow diagram

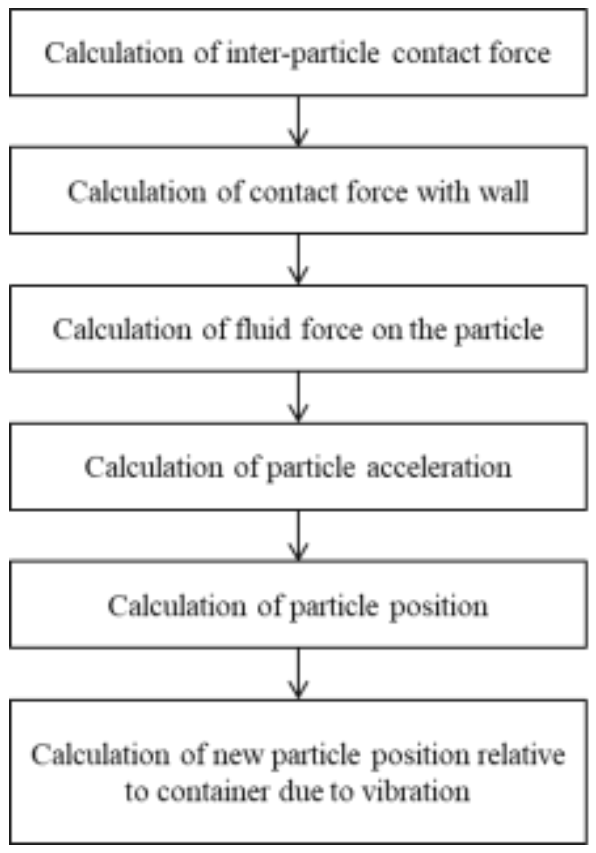

(b) Particle motion flow diagram

Figure 2: Calculation flow diagram 
All conditions of simulation in this work are shown in Table 2.

Table 2: Conditions of simulation

\begin{tabular}{|c|c|c|}
\hline $\begin{array}{c}\text { Superficial gas } \\
\text { velocity }(\mathrm{m} / \mathrm{s}) \\
\end{array}$ & $\begin{array}{l}\text { Amplitude of vibration } \\
(\mathrm{mm})\end{array}$ & Frequency of vibration $\left(\mathrm{s}^{-1}\right)$ \\
\hline \multirow{7}{*}{0.6} & 0 & - \\
\hline & \multirow{2}{*}{1.6} & 37.5 \\
\hline & & 75 \\
\hline & \multirow{2}{*}{2.7} & 37.5 \\
\hline & & 75 \\
\hline & \multirow{2}{*}{4.25} & 37.5 \\
\hline & & 75 \\
\hline \multirow{7}{*}{1.2} & 0 & - \\
\hline & \multirow{2}{*}{1.6} & 37.5 \\
\hline & & 75 \\
\hline & \multirow{2}{*}{2.7} & 37.5 \\
\hline & & 75 \\
\hline & \multirow{2}{*}{4.25} & 37.5 \\
\hline & & 75 \\
\hline \multirow{7}{*}{1.8} & 0 & - \\
\hline & \multirow{2}{*}{1.6} & 37.5 \\
\hline & & 75 \\
\hline & \multirow{2}{*}{2.7} & 37.5 \\
\hline & & 75 \\
\hline & \multirow{2}{*}{4.25} & 37.5 \\
\hline & & 75 \\
\hline
\end{tabular}

\section{RESULTS AND DISCUSSIONS}

\subsection{Program Validation}

This part is divided into particle motion investigation and drying behavior validation. The results from the both simulations are compared with the experimental results from the previous works [1], [6]. Nevertheless, the configuration of the fluidization chamber in the drying behavior validation is not equal to the chamber that set in the experiment. The fluidization chamber used in the simulation was scaled down to reduce the number of the particle and save the computation time.

The effect of amplitude on the drying rate at a given frequency is more complicated. The simulation result is quite similar when compare with the experimental result. It can be noticed that the drying rate of both experimental and simulation trend to decrease with increase amplitude of vibration at low value (1.6-2.7 mm.). However, the trend of changing of drying rate are opposite at higher amplitude of vibration. The drying rates were increased at the higher range of amplitude. It is interesting that the effect of amplitude at a given frequency is more influence at high value of amplitude.

\subsection{Effect of operating parameters}

\subsubsection{Stationary fluidized bed dryer}

The bed configurations for stationary bed at each superficial gas velocity are shown in Figures 3-5. The results are shown in animation style as the time progress corresponding to each superficial gas velocity. At superficial gas velocity equal to $0.6 \mathrm{~m} / \mathrm{s}$, the bed did not fluidized but circulates smoothly. The bed configuration was not change with time at this state. Beside, gas could not flow through the particles well so gas-solid contact was low as well as the heat transfer coefficient. 
The snapshots show that heat transfer between fluid and particles first occurred at the center of the bed near orifice and extended to the neighbor section. Obviously, the temperature of the particle at the bottom near the orifice is heated up while the particle in the dead zone at the edges of the chamber still remained at the initial temperature. At the dead zone, gas did not flow through the bed so the particle was not moved and no heat transfer considered in this zone. It can be noticed that the particle is heated to the wet-bulb temperature of the gas and the drying in constant rate period was started. At this state, the temperature of the particle was constant. Increasing superficial velocity to 1.2 and $1.8 \mathrm{~m} / \mathrm{s}$ significantly improved the heat transfer and the particle motion can be observed. Fluidized behavior of the bed can also be seen. Therefore, the minimum fluidization velocity should be in the range of $0.6-1.2 \mathrm{~m} / \mathrm{s}$. It agrees with the result from the calculation that minimum fluidized is about $0.62 \mathrm{~m} / \mathrm{s}$ while the terminal velocity of the particle is $6.88 \mathrm{~m} / \mathrm{s}$. It is similar in all cases that the temperature of the particle at the center near the orifice was heated up firstly while the temperature of the particle at the edge of the chamber lastly increased.
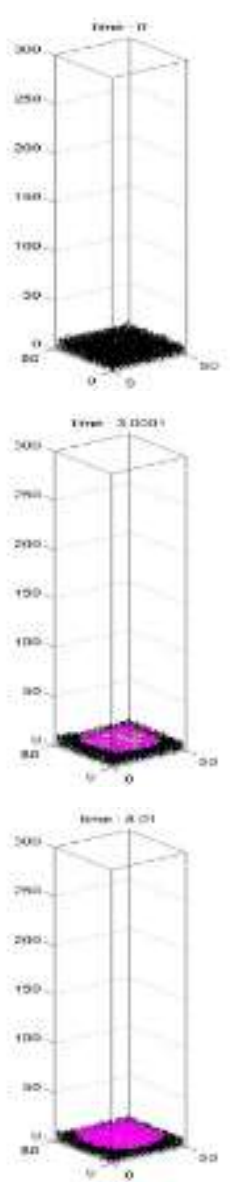

Figure 3: Snapshots of fluidization behavior at $\mathrm{U}_{0}=0.6 \mathrm{~m} / \mathrm{s}, \mathrm{f}=0 \mathrm{~s}^{-1}$
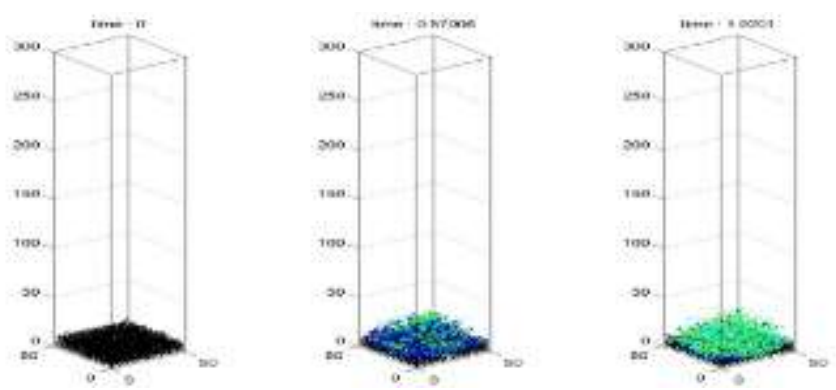

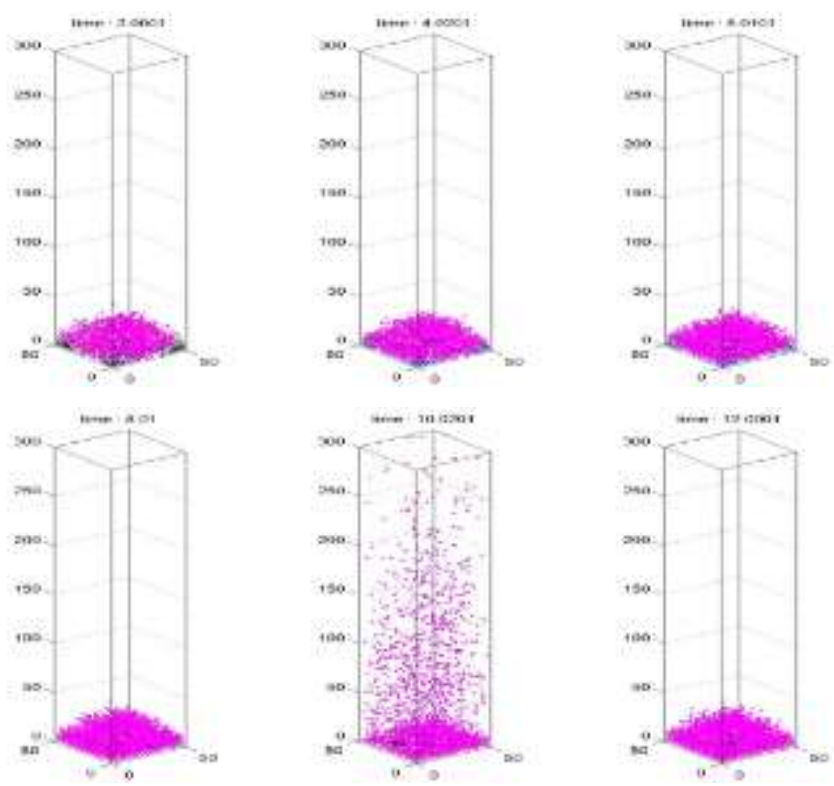

Figure 4: Snapshots of fluidization behavior at $\mathrm{U}_{0}=1.2 \mathrm{~m} / \mathrm{s}, \mathrm{f}=0 \mathrm{~s}^{-1}$
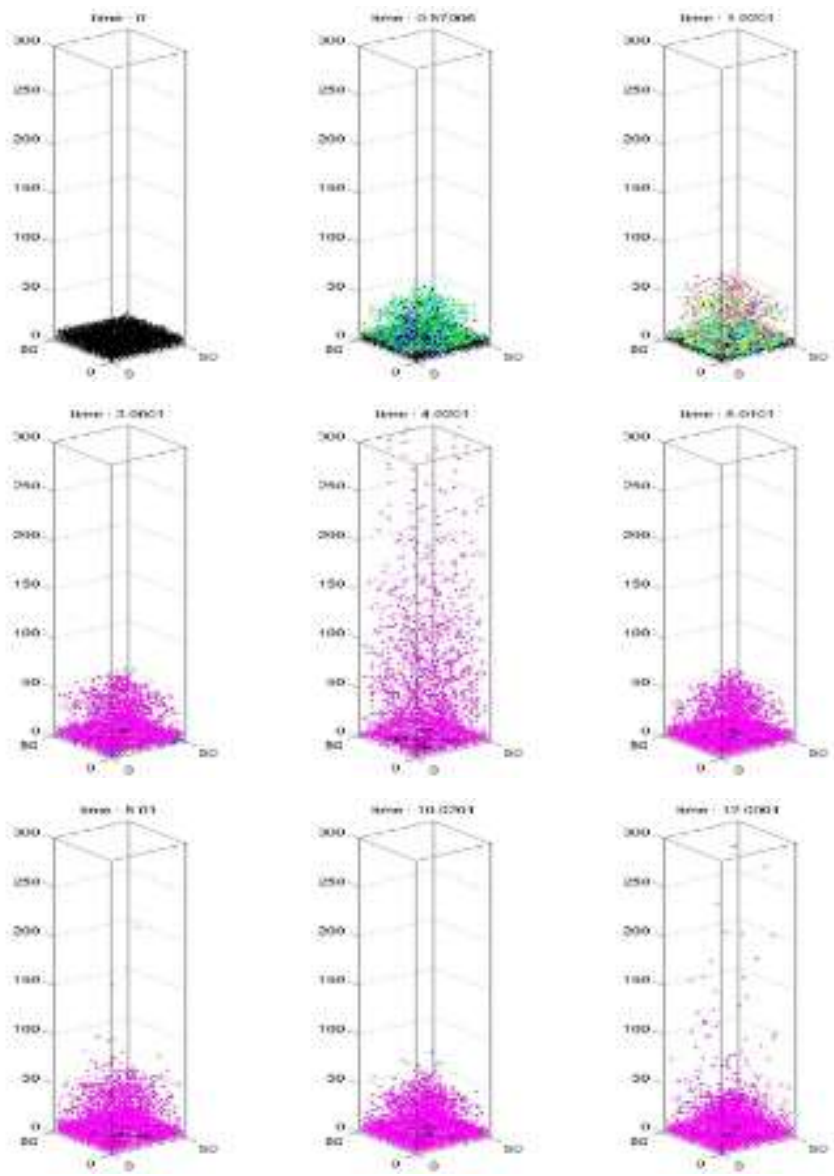

Figure 5: Snapshots of fluidization behavior at $\mathrm{U}_{0}=1.8 \mathrm{~m} / \mathrm{s}, \mathrm{f}=0 \mathrm{~s}^{-1}$
- $<299.15 \mathrm{~K}$
- $299.15-300.15 \mathrm{~K}$
- 300.15-301.15 K
- $301.15-302.15 \mathrm{~K}$
$302.15-303.15 \mathrm{~K}$
- $303.15-304.15 \mathrm{~K}$
- $>304.15 \mathrm{~K}$

The fluidization of the bed can be noticed by the changing of the void fraction with time at different height. The calculation space of void fraction was $50 \mathrm{~mm}$ in width, $50 \mathrm{~mm}$ in depth, and $20 \mathrm{~mm}$ in height for each position in y direction of fluidized bed. The void fraction of bed at superficial velocity $0.6 \mathrm{~m} / \mathrm{s}$ is slightly change with time because the 
bed behaves like a pack bed. Increasing superficial velocity to 1.2 and $1.8 \mathrm{~m} / \mathrm{s}$, the bed was fluidized so the change in void fraction near the bottom section can be observed. And the result demonstrated that the drying rate was improved quite linearly with increase in inlet air velocity.

An improvement in heat transfer between the particle and gas increases is due to improving in fluidization behavior and resulting in the increasing of drying rate.

\subsubsection{Vibrated fluidized bed dryer}

\subsubsection{Effect of superficial gas velocity}

Figures 6-8 are the snapshots obtained from simulation with equal in frequency $\left(37.5 \mathrm{~s}^{-1}\right)$ and amplitude (1.6 $\mathrm{mm}$ ) of vibration but different in superficial velocity. The particle movements in all cases have the same manner. The particles are fluidized and pulsatory motion can be seen around the center of the chamber. It can be noticed that the dead zones at the corners of the fluidization chamber can be eliminated by an introducing of vibration. Thus, the gas can flow through and heat all the particles in the fluidized bed. When compare the particle motion of the vibrated fluidized bed (Figures 6-8) and stationary fluidized bed (Figures 3-5), it is recognized that the heat transfer in the vibrated fluidized bed is improved due to the fluidization behavior.
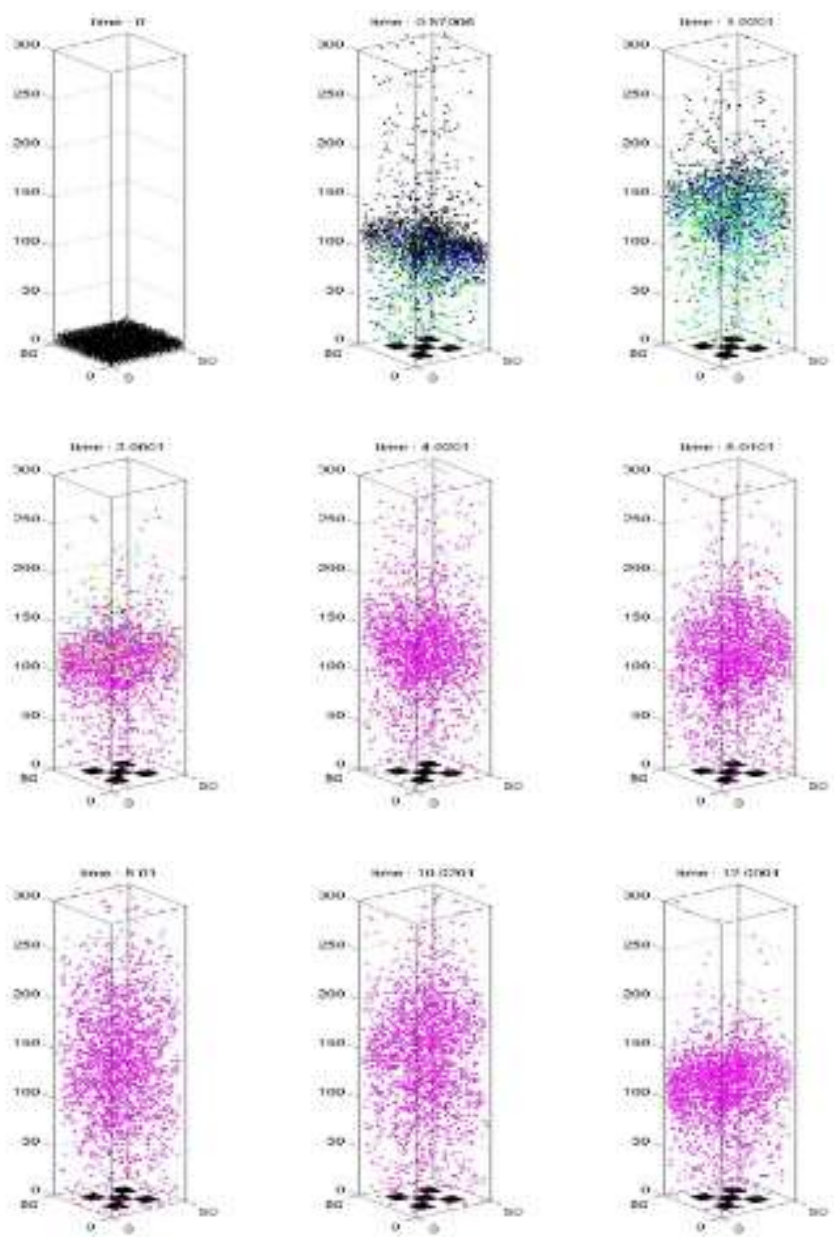

Figure 6: Snapshots of fluidization behavior at $\mathrm{U}_{0}=0.6 \mathrm{~m} / \mathrm{s}, \mathrm{a}=1.6 \mathrm{~mm}, \mathrm{f}=37.5 \mathrm{~s}^{-1}$ 

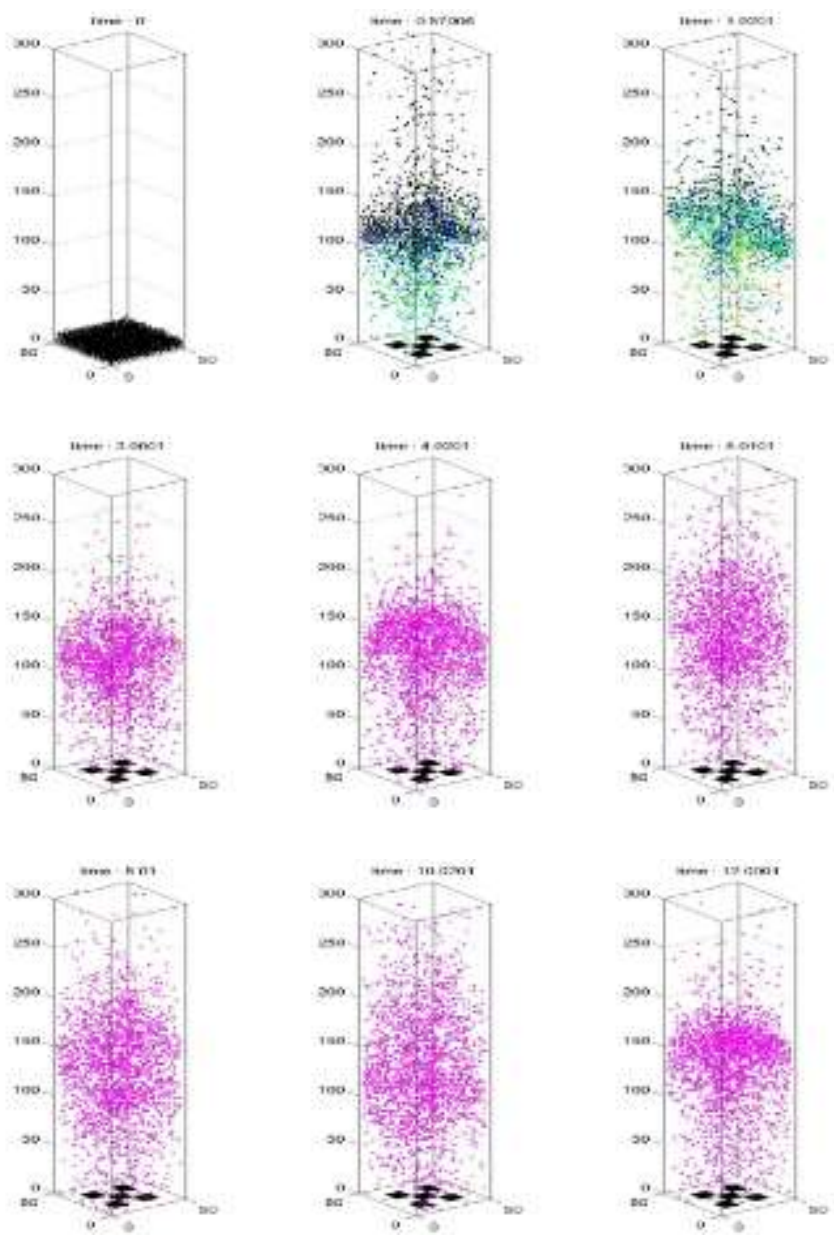

Figure 7: Snapshots of fluidization behavior at $\mathrm{U}_{0}=1.2 \mathrm{~m} / \mathrm{s}, \mathrm{a}=1.6 \mathrm{~mm}, \mathrm{f}=37.5 \mathrm{~s}^{-1}$
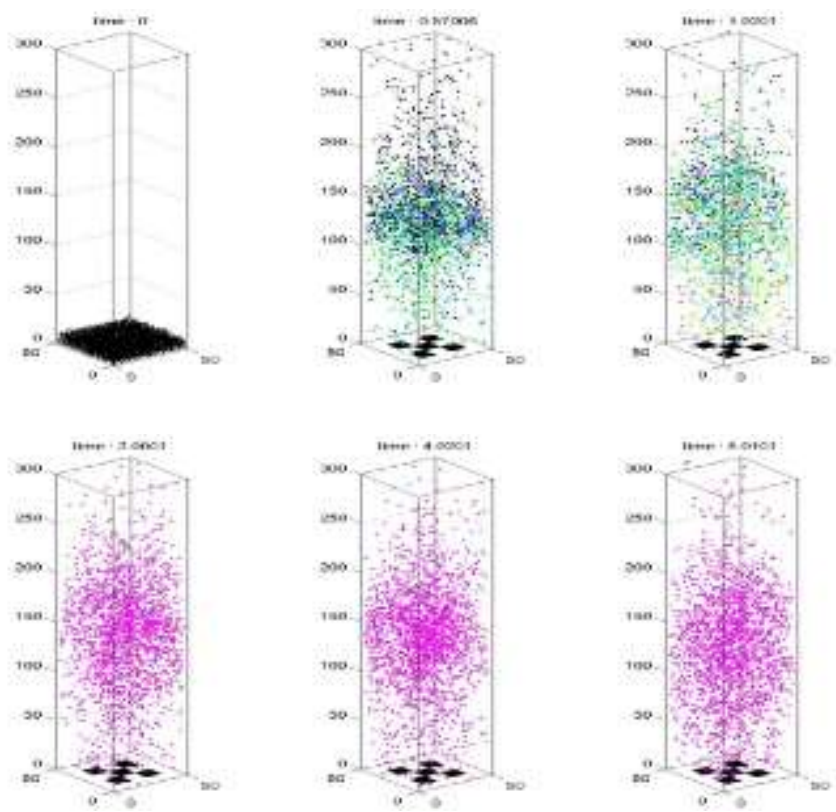

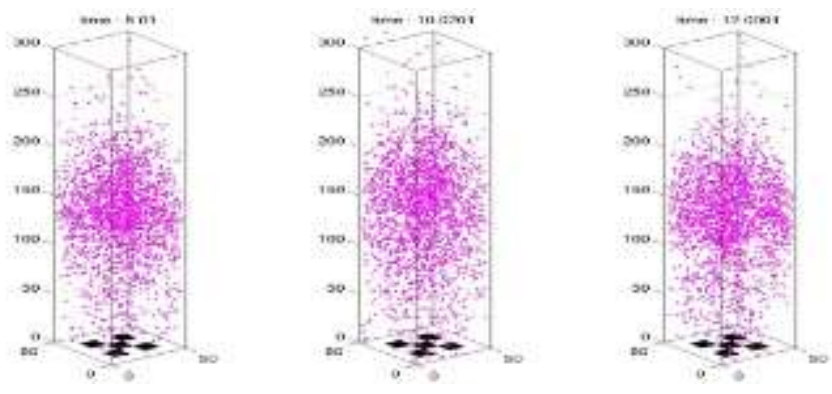

Figure 8: Snapshots of fluidization behavior at $\mathrm{U}_{0}=1.8 \mathrm{~m} / \mathrm{s}, \mathrm{a}=1.6 \mathrm{~mm}, \mathrm{f}=37.5 \mathrm{~s}^{-1}$

At superficial velocity $0.6 \mathrm{~m} / \mathrm{s}$, the bed is fluidized and the particles are moved and distributed in between 100-150 $\mathrm{mm}$ of bed height. When increase superficial velocity, the particle motion inside the bed behaves like to the case of superficial velocity $0.6 \mathrm{~m} / \mathrm{s}$ except that particles are more distributed. From Figures 6-8, the bed reaches the vaporizing temperature faster after increasing the superficial velocity. For the effect of superficial velocity on rate of drying, it can be implied that the heat transfer inside the vibrated fluidized bed increase with increase in superficial velocity. It can be noticed that superficial velocity has high influence to the rate of drying at low amplitude of vibration but the effect decrease at higher amplitude of vibration. This observation may occur because the bed is fully fluidized at high value of amplitude of vibration. At low value of amplitude of vibration, the fluidization behavior of the bed still can be improved with increasing of superficial gas velocity. Moreover, the simulation indicates that at different frequency of vibration, the effect of superficial velocity is not different.

\subsubsection{Effect of amplitude of vibration}

Figures 6,9 and 10 are the simulation at the same of the superficial velocity $(0.6 \mathrm{~m} / \mathrm{s})$ and the frequency of vibration $\left(37.5 \mathrm{~s}^{-1}\right)$ but different in amplitude of vibration. In all cases, the particles are fluidized and distributed around the center of the chamber. There is no observing of dead zones at the corners of the fluidization chamber because of vibration.
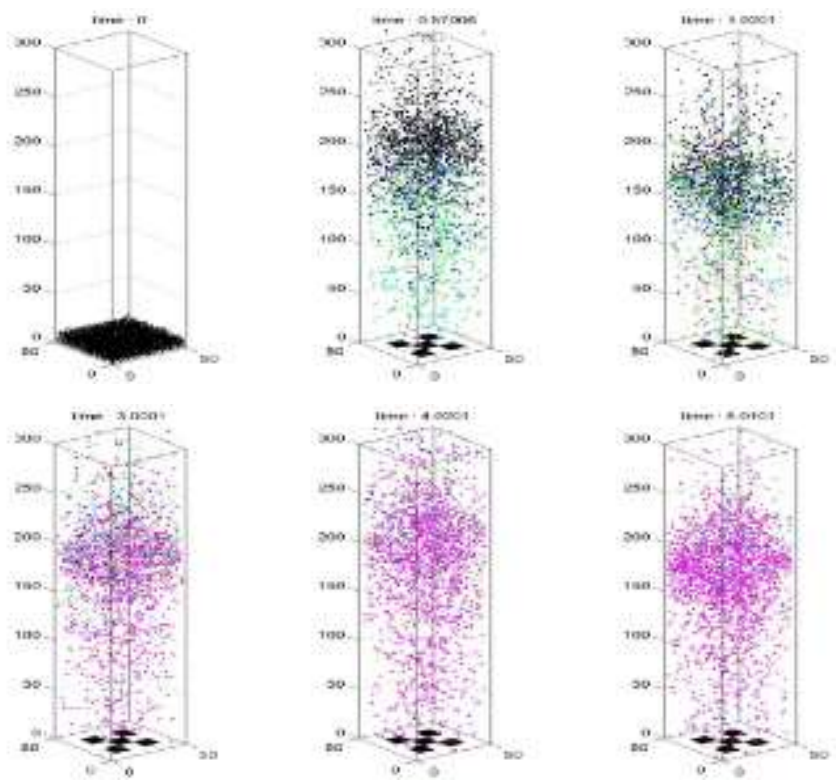

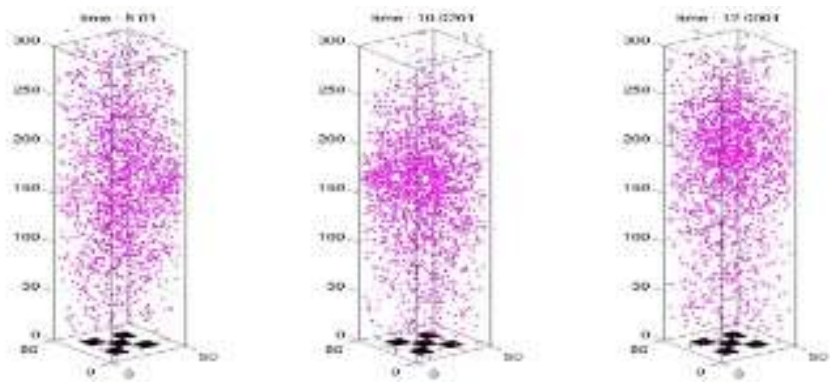

Figure 9: Snapshots of fluidization behavior at $U 0=0.6 \mathrm{~m} / \mathrm{s}, \mathrm{a}=2.7 \mathrm{~mm}, \mathrm{f}=37.5 \mathrm{~s}^{-1}$
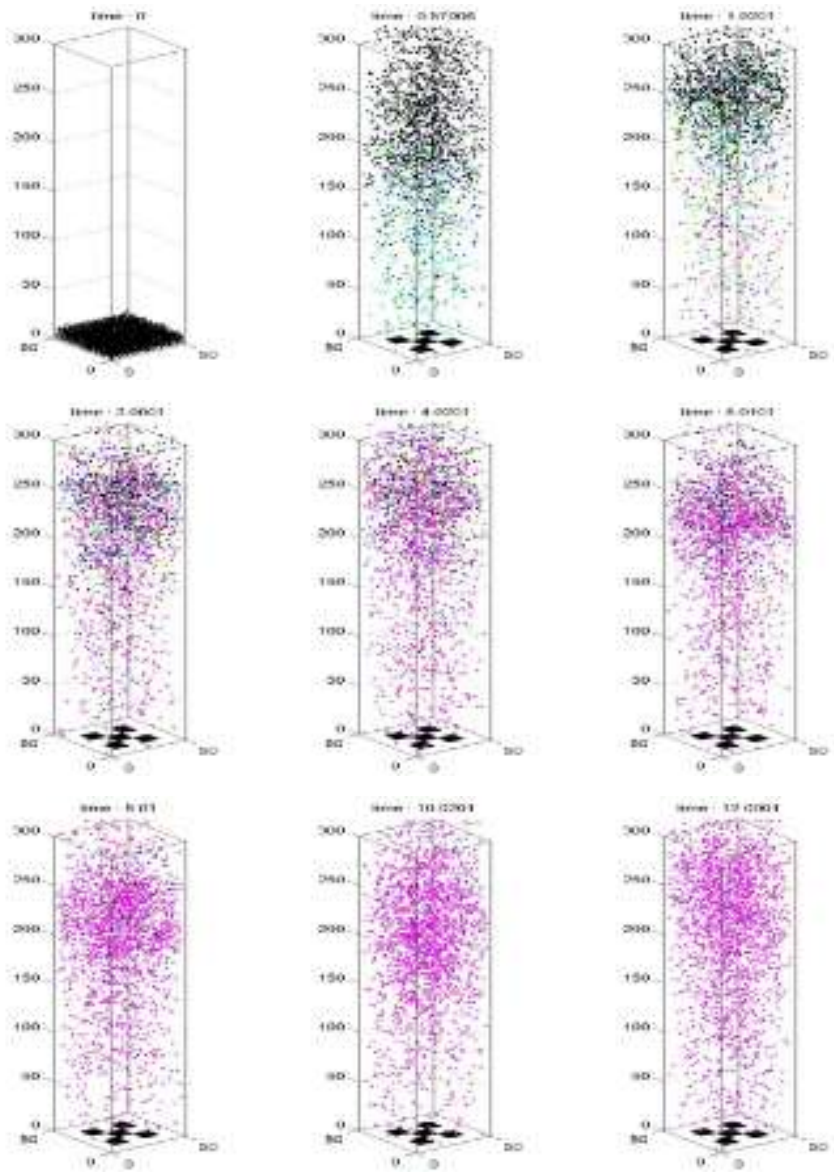

Figure 10: Snapshots of fluidization behavior at $\mathrm{U}_{0}=0.6 \mathrm{~m} / \mathrm{s}, \mathrm{a}=4.25 \mathrm{~mm}, \mathrm{f}=37.5 \mathrm{~s}^{-1}$

At amplitude of vibration equal to $1.6 \mathrm{~mm}$, the bed is fluidized and the particles are distributed and fluctuated in between 100-150 mm of bed height. At each amplitude of vibration, the particle motions are not quit different except that level of fluctuation of particles increase with increase in amplitude. Therefore, the rate of drying is not improved when increase amplitude of vibration. From Figures 6, 9 and 10, it indicates that heat transfers in the last two cases are lower than that in the first case since the particles in the bed at amplitude of vibration $1.6 \mathrm{~mm}$ reach to the wet-bulb temperature of the inlet air first. Moreover, the changing of drying rate decreases with amplitude and the slope of decrease in drying rate is steep at high value of superficial gas velocity. It may expect that the heat transfer decrease when the amplitude of vibration is increased because the size of fluidization chamber in the simulation is too short. At the low amplitude of vibration, most of the particles are fluidized inside the fluidized bed chamber. The number of particle move out of the boundary of the chamber is increased when the amplitude of vibration or superficial gas velocity is increased. From the results, it may be implied that these are only minor effect from amplitude of vibration on drying rate at every frequency of vibration, since the bed configuration at low and high frequency of vibration is similar because they have already fully fluidized. 


\subsubsection{Effect of frequency of vibration}

Figures 4, 7 and 11, which are the snapshots obtained from simulation with the same of superficial velocity $(1.2 \mathrm{~m} / \mathrm{s})$ and amplitude of vibration $(1.6 \mathrm{~mm})$ but the different frequencies As mention above, the bed configuration is not quit change with time at no frequency of vibration. The snapshots show heat transfer between fluid and particles first occurs at the center of the bed near orifice and spread out. The temperature of the particle at the bottom near the orifice is heated up while the temperature of the particle at the edge of the chamber is still remaining. From Figures 7 and 11 there is no dead zone observed at the edge of the chamber. When introducing the vibration to the bed, the particle motions are not quit different. The bed is fully fluidized at frequency of vibration equal to $37.5 \mathrm{~s}^{-1}$, so increasing the frequency could not improve the heat transfer. Therefore, the rate of drying is not increased when increase frequency of vibration.
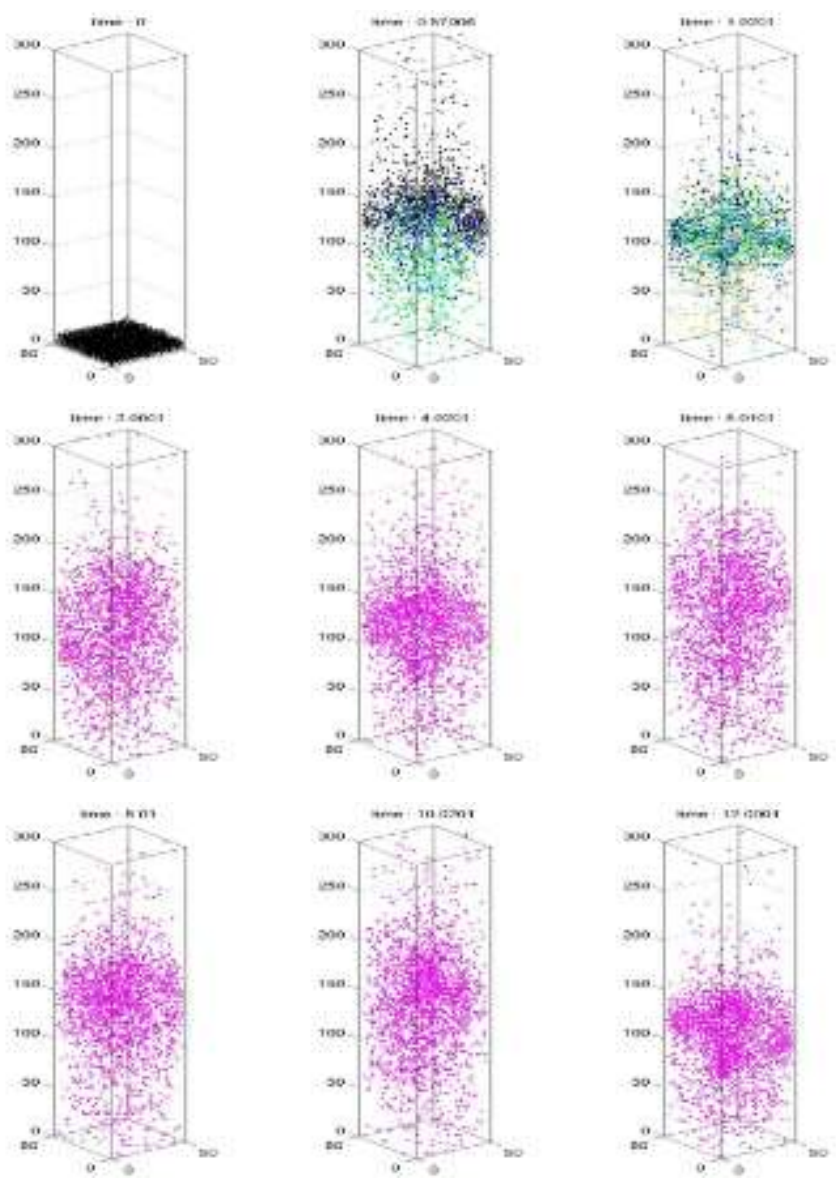

Figure 11: Snapshots of fluidization behavior at $U_{0}=1.2 \mathrm{~m} / \mathrm{s}, \mathrm{a}=1.6 \mathrm{~mm}, \mathrm{f}=75 \mathrm{~s}^{-1}$

\section{CONCLUSION}

A vibrated fluidized bed is an effective tool for handling the fluidization of agglomerative particle or particles that have wide range of particle size distribution. Vibration improves the fluidization behavior, efficiency of gas-solid contact and heat transfer. In this work, the program based on the combination approach of DEM-CFD that can simulate the simultaneous momentum, heat and mass transfer in a vibrated fluidized bed was developed using C-Programming. The simulation results were visualized by MATLABTM. The calculation of the hydrodynamic inside the vibrated fluidized bed dryer was separated into 2 major parts, which are particle motion and fluid motion, The DEM was applied to calculate the interaction forces between particle-particle and particle-wall contact. Then, the Newton's second law of motion was applied to calculate the particle motion. The fluid motion was calculated using CFD which based on local 
averaged quantities. The numerical simulation can give more data for each particle than that obtained from an experiment.

The program was developed firstly and tested with some artificial cases. Then the drying behavior from the simulation was validated with an experiment of Gupta et al [1]. It showed that the programming gives realistic results of the particle movement and the drying behaviors. Next, the developed program was applied to study the effect of superficial gas velocity (U0), frequency of vibration (f) and amplitude of vibration (a) in fluidized bed.

From the result of the case that velocities $0.6 \mathrm{~m} / \mathrm{s}$ and no vibration of bed, particles in the bed were not fluidized but smoothly circulate. Thus, the particles were not well mixed and the heat transfer occurred only near the orifice. When increased superficial gas velocity, the fluidization of the particles was observed. The mixing of particles was improved as well as the heat transfer and drying rate. The introduction of vibration improved the fluidization behavior. The particles in the bed were well mixed and the particle temperature was highly distributed. During study of the effect of amplitude of vibration, the size of fluidization chamber in the simulation was too short to accommodate the particles motion. Some of the particles moved beyond the boundary of the chamber when the chamber was strongly vibrated. The particles that move out of the chamber could not receive heat from the feed gas and their average drying rate dropped. Therefore, the drying rate decreased according to increased in amplitude of vibration. For the effect of frequency on the drying rate, it can be seen that the particle motion at frequency $37.5 \mathrm{~s}^{-1}$, which the fully fluidization was observed, slightly changed when the frequency of vibration increased. From the results, it can be concluded that increasing of frequency and amplitude of vibration could not significantly improve rate of drying.

\section{NOTATION}

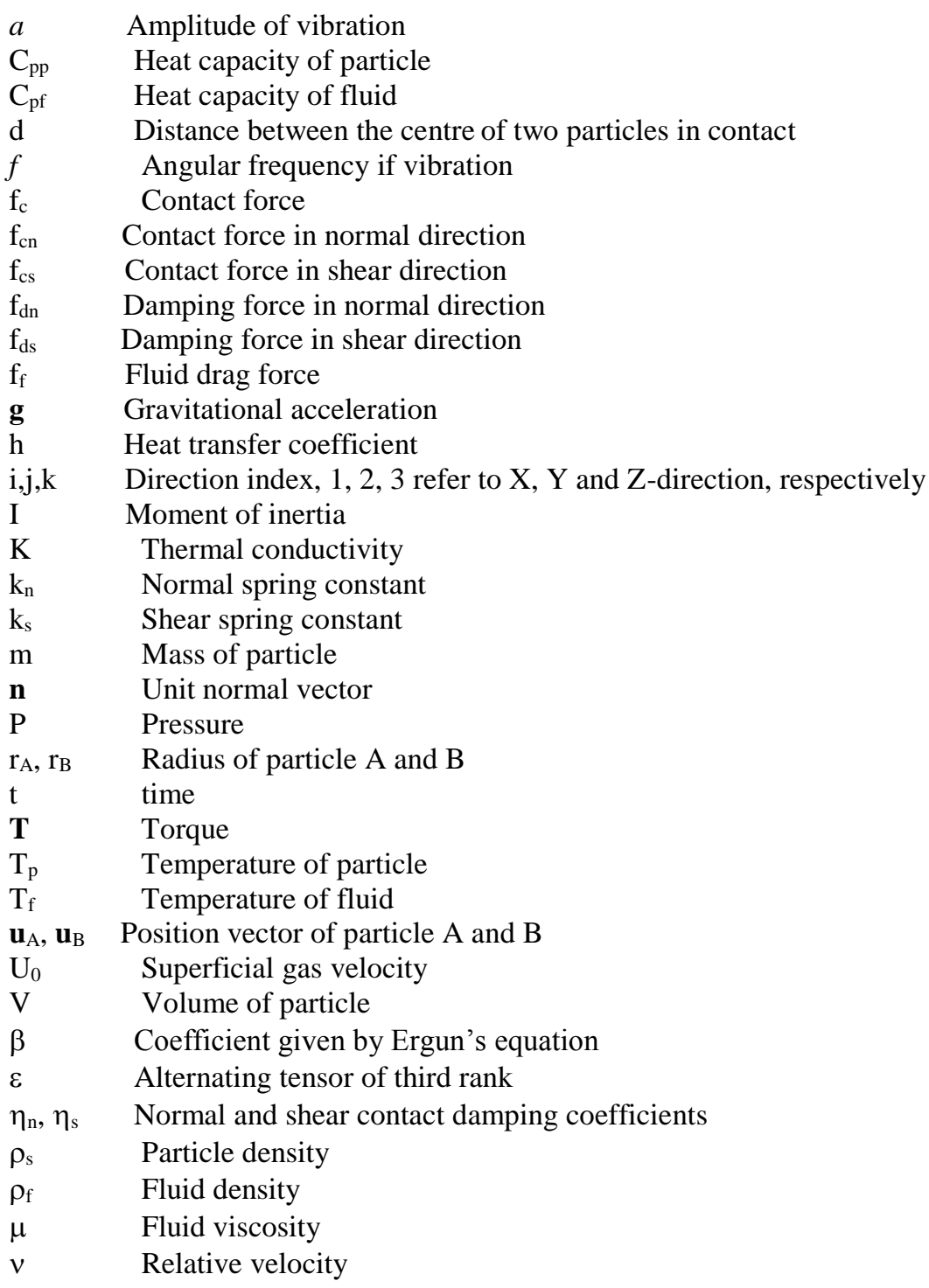


$v_{\mathrm{n}} \quad$ Relative velocity in normal direction

$v_{\mathrm{t}} \quad$ Relative velocity in tangential direction

$v_{\mathrm{s}} \quad$ Relative velocity in shear direction

$\bar{v}_{\mathrm{p}, \mathrm{i}} \quad$ Averaged particle velocities

$\omega \quad$ Angular velocity of the centre of sphere B with respect to A

\section{REFERENCES}

[1] Gupta, R., Peter, L. and Mujumdar, A.S., 1982, "Drying of Granular Materials in aVibrated Fluidized Bed", Drying' 82, Edited by Mujumdar, A.S., New York, Hemisphere, pp. 141-150

[2] Cundall, P.A. and Strack, O.D.L., 1979, “A Discrete Numerical Model for Grannular Assemblies”, Geotechnique, Vol. 29, No. 1, pp. 47-65.

[3] Versteeg, H.K. and Malalasekera, W., 1995, An Introduction to Computational Fluid Dynamics ; The Finite Volume Method, Longman Scientific \& Technical.

[4] Ergun, S., 1952, Chemical Engineering Progress, Vol. 48, No. 2.

[5] Wen, C.Y. and Yu, Y.H., 1996, Chemical Engineering Progress, Series 62, Vol. 62.

[6] Asmar, B.N., Langston, P.A., Matchett, A.J. and Walters, J.K., 2002, "Validation Tests on a Distinct Element Model of Vibrating Cohesive Particle Systems", Computers \& Chemical Engineering, Vol. 26, pp. 785-802. 